\title{
RANCANG BANGUN SISTEM MONITORING GAS ALKOHOL PADA FERMENTASI KETAN BERBASIS SENSOR TGS 2620
}

\author{
Maulana Kussuma Negara1), Rahadi Wirawan ${ }^{1)}$, Nurul Qomariyah" \\ 1)Program Studi Fisika, FMIPA, Universitas Mataram, Mataram, NTB, Indonesia \\ Corresponding author :Nurul Qomariyah \\ E-mail : nurulqomariyah@unram.ac.id
}

\section{Diterima 09 November 2020, Disetujui 14 November 2020}

\begin{abstract}
ABSTRAK
Penelitian ini bertujuan untuk merancang sistem monitoring gas alkohol pada proses fermentasi ketan berbasis sensor TGS 2620. Sistem monitoring terdiri dari sensor TGS 2620, modul Arduino Uno, modul Data Logger dan wadah fermentasi. Pengujian sistem menggunakan variasi ragi $0,5 \%, 1,0 \%$, dan 1,5 $\%$ pada 100 gram ketan dengan waktu monitoring selama tiga hari. Sistem monitoring memiliki karakteristik akurasi pengukuran 98,33\%, tingkat presisi 99,79\%, warmup selama 3,75 menit, dan response time 10,83 menit. Hasil monitoring konsentrasi alkohol menunjukkan bahwa kadar alkohol semakin meningkat seiring meningkatnya kadar ragi dan waktu inkubasi. Kadar alkohol terukur antara $0,73 \%$ sampai $1,63 \%$.
\end{abstract}

Kata kunci:sensor TGS 2620; fermentasi; monitoring.

\begin{abstract}
This study aims to design a monitoring system for alcohol gas in the glutinous rice fermentation process based on the TGS 2620 sensor. The monitoring system consists of the TGS 2620 sensor, the Arduino Uno module, the Data Logger module, and the fermentation container. Testing the system using yeast variations of $0.5 \%, 1.0 \%$, and $1.5 \%$ on 100 grams of glutinous rice with three days of monitoring time. The monitoring system has the characteristics of a $98.33 \%$ accuracy level, a precision level of $99.79 \%$, heating 3.75 minutes, and response time of 10.83 minutes. The results of monitoring the alcohol concentration showed that the alcohol content increased with the increasing yeast level and incubation time.. A measured alcohol content is about $0.73 \%$ to $1.63 \%$.
\end{abstract}

Keywords: sensor TGS 2620; fermentation; monitoring.

\section{PENDAHULUAN}

Proses fermentasi pada pembuatan tape ketan merupakan pencampuran bahan dasar berupa beras ketan dengan ragi sebagai agen fermintasi (Cahyadi, 2006). Pada proses tersebut dihasilkan alkohol yang kadarnya bergantung jumlah ragi yang diberikan dan lamanya proses fermintasi(Berlian et al., 2016). Kandungan alkohol pada tape ketan harus memenuhi regulasi Permenkes RI No. 86/Menkes/Per/IV/1997 (Peraturan Menteri Kesehatan RI Nomor 86/Men,Kes/PER/ IV/1997 Tentang Minuman Keras, 2018) dimana kadar alkohol (etanol) kurang dari 5\%. Adanya batasan kandungan alkohol dalam suatu makanan mengakibatkan perlu dilakukannya pengukuran alkohol pada tape ketan.

Pengukuran kadar alkohol pada tape ketan umumnya dilakukan secara manual menggunakan Alkoholmeter. Menurut Putri (Putri, 2007), rata-rata kadar alkohol yang terkandung di dalam tape ketan setelah proses inkubasi selama tiga hari berkisar 1,4\%-1,9\%. Sedangkan menurut Zainal Berlian, dkk. (Berlian et al., 2016) perubahan kadar alkohol pada proses fermentasi semakin meningkat seiring dengan penambahan konsentrasi ragi. Pengukuran perubahan kadar alkohol pada proses fermentasi ketan harus dilakukan secara real time . Oleh karenanya, pengukuran secara manual kurang efektif dalam memonitoring kandungan alkohol. Pengukuran real time memerlukan perangkat monitoring yang mampu merekam perubahan kadar alkohol yang terbentuk dalam proses fermentasi.

Perancangan sistem monitoring kadar alkohol pada proses fermentasi tape ketan dapat memanfaatkan sensor-sensor pendeteksi alkohol. Sensor yang digunakan antara lain, sensor TGS 2620 dan MQ-3 (Rohmanto, 2014; Satria \& Wildan, 2013). Monitoring alkohol pada proses fermentasi tape telah dilakukan oleh Abdillah (Abdillah, 2016), alat tersebut mampu mendeteksi kandungan alkohol dengan rata-rata error pengukuran 
sebesar 3,6\%. Antika (Antika et al., 2018) telah membandingkan unjuk kerja antara kedua sensor tersebut. Hasil yang didapatkan menunjukkan akurasi sensor TGS 2620 lebih tinggi dibandingkan dengan sensor MQ-3. Selain itu, sensor TGS 2620 memiliki harga yang relatif terjangkau (Figaro, 2003).

Penelitian ini berfokus pada perancangan sistem monitoring gas alkohol pada proses fermentasi ketan berbasis sensor TGS 2620.

\section{METODE PENELITIAN}

Sistem monitoring alkohol berbasis sensor TGS 2620 merupakan sensor resistive dan memiliki sensitivitas cukup baik terhadap pendeteksian alkohol. Terdapat empat komponen utama penyusun sistem monitoring gas alkohol pada fermentasi ketan yaitu sensor TGS 2620, Modul Arduino UNO dengan mikrokontroler AtMega328P, Modul Data Logger, dan wadah fermentasi ketan. Sensor TGS 2620 pada sistem berfungsi sebagai monitoring gas alkohol pada proses fermentasi. Mekanisme kerja dari sistem monitoring gas ini yaitu sensor TGS 2620 mendeteksi gas alkohol yang dihasilkan pada saat fermentasi berlangsung dengan keluaran berupa nilai $A D C$. Disain sistem ditampilkan dalam blok diagram pada Gambar 1.

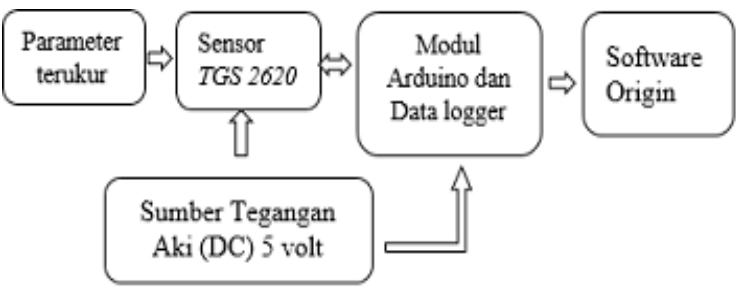

\section{Gambar 1. Diagram blok sistem pendeteksi gas alkohol.}

Nilai $A D C$ yang terbaca pada sensor akan dikonversi menjadi persentase kadar alkohol berdasarkan fungsi kalibrasi. Fungsi kalibrasi tersebut diperoleh dari hasil pengukuran konsentrasi menggunakan alat standar alkoholmeter. Akuisisi data dilakukan setiap rentang waktu 5 menit selama 3 hari yang telah terprogram dalam sketch Arduino.

Pada sistem terdapat tiga buah sensor yang pengoperasiannya dilakukan secara bersamaan untuk me-monitoring kandungan alkohol pada masing-masing variasi ragi yang digunakan. Modul Arduino Uno dan Data Logger berfungsi sebagai perangkat pengendali sistem dan perekam data real time pada saat fermentasi berlangsung. Sementara wadah fermentasi berupa wadah tertutup berbahan kaca yang ditempatkan di dalam kotak styrofoam. Penggunaan kotak styrofoam difungsikan sebagai isolasi untuk mengurangi pengaruh suhu dari luar sistem. Desain perangkat sistem monitoring gas alkohol dapat dilihat pada Gambar 2.

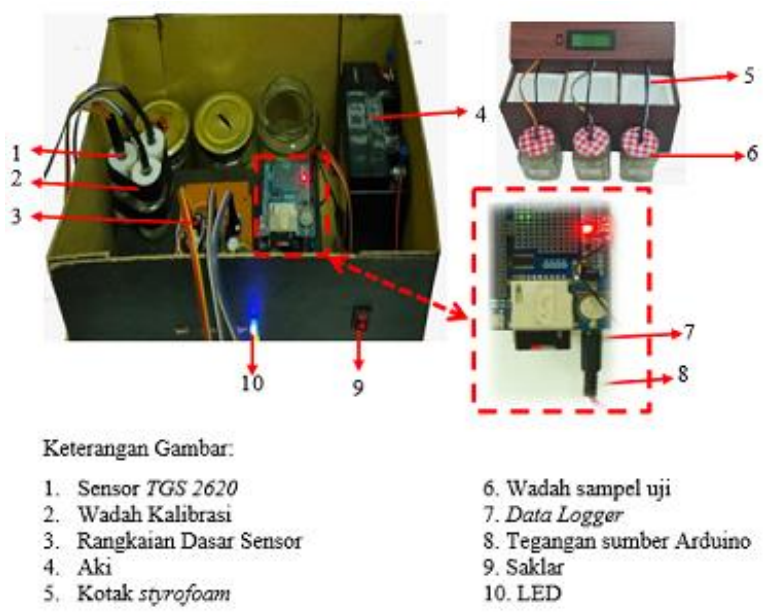

Gambar 2. Perangkat sistem monitoring gas alkohol.

Proses kalibrasi sistem pendeteksi gas alkohol dilakukan dengan membandingkan data pembacaan sampel menggunakan Alkoholmeter. Terdapat lima variasi sampel larutan alkohol yang digunakan yaitu $1 \%, 2 \%$, $3 \%$, 4\%, dan 5\%. Proses pengalibrasian sistem dilakukan dengan cara mendekatkan sensor \pm $2 \mathrm{~cm}$ dari sampel larutan alkohol selama 17 menit, sehingga didapatkan hasil pembacaan sensor terhadap kelima sampel larutan. Performa sensor dalam me-monitoring kadar alkohol selama proses inkubasi dilihat dari nilai akurasi, presisi, lama waktu pemanasan, dan waktu respon selama pengukuran. Perubahan kandungan gas alkohol ketika proses fermentasi dilakukan pada tiga variasi sampel ragi yang di berikan yaitu $0,5 \%, 1,0 \%$, dan $1,5 \%$ pada 100 gram ketan

\section{HASIL DAN PEMBAHASAN}

Pembacaan sensor TGS 2620 terhadap kadar alkohol selama proses fermintasi berupa nilai $A D C$. Hubungan perubahan nilai $A D C$ dengan persentase kadar alkohol dapat dimodelkan melalui pendekatan kurva logaritmik (Aditama et al., 2020), sehingga didapatkan fungsi alih. Fungsi alih tersebut digunakan sebagai fungsi konversi antara nilai $A D C$ dengan persentase alkohol, sehingga sistem akan mampu membaca konsentrasi alkohol secara langsung. Hubungan pembacaan nilai sensor TGS 2620 dengan alkoholmeter sebagai alat ukur standar ditampilkan pada Gambar 3. 


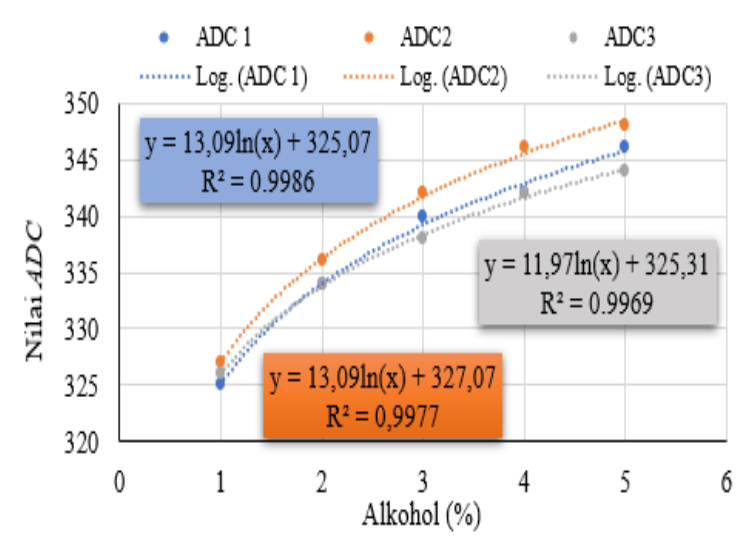

Gambar 3. Grafik hubungan persentase alkohol dengan nilai ADC.

Proses pendeteksian alkohol oleh sensor yaitu dengan cara membaca hasil perubahan resistivitas yang di wakilkan oleh nilai $A D C$. Nilai $A D C$ yang terbaca akan berbanding lurus dengan kadar gas alkohol yang diterima oleh sensor. Semakin tinggi kadar gas yang terbaca menyatakan bahwa sensor mengalami reaksi oksidasi sehingga konduktivitas meningkat, dan resistivitas akan berkurang.

Gambar 4 menunjukkan grafik pendeteksian gas alkohol pada ketiga sensor yang digunakan. Ketika sensor dalam keadaan base line (belum diberikan alkohol) pembacaan nilai $A D C$ akan berfluktuasi. Hal tersebut dikarenakan sensor memerlukan waktu pemanasan (warmup) selama beberapa saat sebelum sensor dapat beroperasi secara baik. Pada saat pemberian sampel, nilai $A D C$ untuk semua sensor akan meningkat sesuai dengan konsentrasi larutan yang digunakan. Sedangkan, pada saat sensor dijauhkan dari sampel larutan, nilai $A D C$ sensor akan kembali menurun (recovery time) hingga pada kondisi awal (Aditama et al., 2020).

Response time merupakan waktu yang dibutuhkan sensor untuk dapat membaca suatu data $(A D C)$ pada saat sensor diberikan sampel larutan. Dalam hal ini, penentuan Response time sensor TGS 2620 ditentukan pada saat sensor membaca nilai $A D C$ maksimum. Hasil yang didapatkan yaitu untuk setiap konsentrasi alkohol memiliki Response time yang berbedabeda. Konsentrasi alkohol yang tinggi akan menghasilkan Response time semakin cepat.

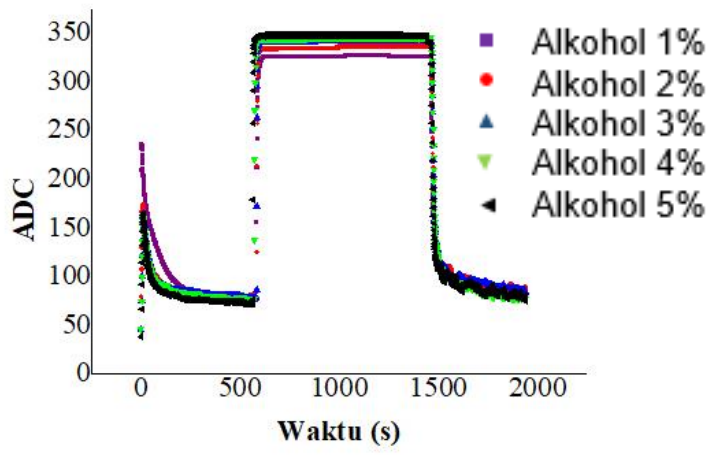

(a)

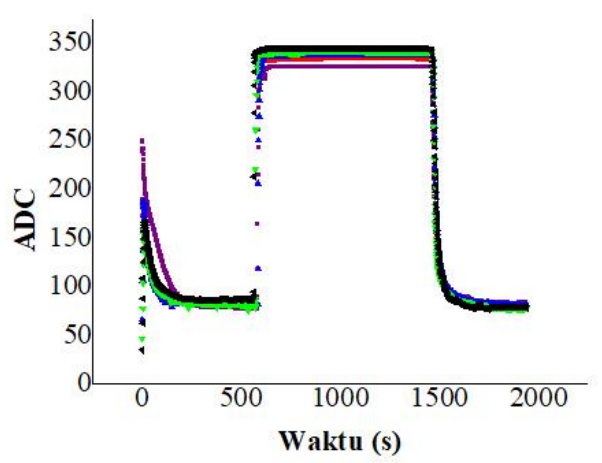

(b)

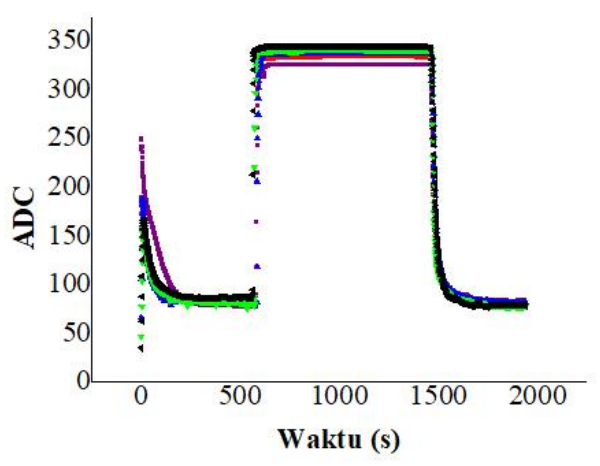

(c)

Gambar 4. Pendeteksian gas alkohol pada Sensor: a) Sensor 1, b) Sensor 2, c) Sensor 3.

Akurasi sensor pada masing-masing sensor adalah sebagai berikut: Sensor 1 memiliki akurasi sebesar $98,33 \%$, Sensor 2 memiliki akurasi sebesar $98,28 \%$, dan Sensor 3 memiliki akurasi sebesar 96,29 \%. Data tersebut menunjukkan sensor memiliki akurasi yang tinggi pada pembacaan konsentrasi gas alkohol. Sedangkan untuk penentuan presisi sensor didapat dengan cara me-monitoring sampel larutan kalibrasi selama kurang lebih 15 menit, dan diperoleh nilai presisi data tidak jauh berbeda untuk masing-masing sensor yaitu: Sensor 1 sebesar 99,79\%, Sensor 2 sebesar $99,77 \%$, dan Sensor 3 dengan presisi data sebesar $99,74 \%$. Adapun waktu pemanasan 
untuk sistem monitoring alkohol selama 3,75 menit (Gambar 5). Sensor yang terdapat pada sistem monitoring alkohol akan stabil setelah melewati waktu pemanasan tersebut. Oleh karena itu pengambilan data untuk memonitoring kandungan alkohol pada fermentasi ketan dilakukan pemanasan sensor dengan selang waktu tersebut.

\section{Monitoring Kandungan Alkohol pada Proses Fermentasi}

Dilakukan pengukuran kadar alkohol dengan sistem monitoring berbasis sensor TGS 2620 selama proses fermentasi ketan dengan jangka waktu inkubasi tape selama 3 hari. Terdapat tiga variasi sampel tape ketan, dengan masing-masing tape diberikan persentase kandungan ragi yang berbeda-beda $(0,5 \%, 1,0 \%$ dan $1,5 \%)$ pada 100 gram ketan. Hasil pengujian sistem monitoring alkohol pada fermentasi ketan pada penelitian ini ditampilkan setiap 5 menit yang telah diatur pada program Arduino).

Pada Gambar 5 dapat diketahui bahwa pada sampel dengan persentase ragi yang tinggi akan mampu menghasilkan kadar alkohol yang relatif lebih cepat. Pada penelitian ini sampel tape ketan yang diberikan ragi terbanyak mampu menghasilkan gas alkohol tercepat yaitu saat waktu inkubasinya adalah 3,9 jam yang didapatkan pada sampel dengan jumlah ragi $1,5 \%$. Hal ini disebabkan karena kandungan ragi yang semakin banyak memiliki bakteri sebagai agen fermentasi yang semakin banyak pula, sehingga menghasilkan waktu reaksi fermentasi yang lebih cepat (Berlian et al., 2016).

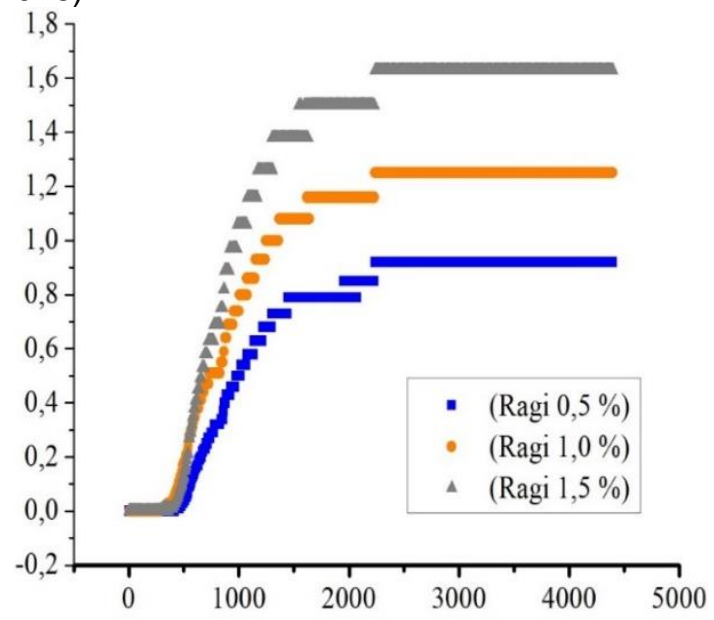

Gambar 5. Grafik PerubahanPersentase Alkohol Terhadap Waktu inkubasi.

Hasil pengamatan menunjukkan bahwa fermentasi ketan memerlukan total waktu inkubasi secara keseluruhan yaitu 37,25 jam untuk mendapatkan hasil persentase alkohol yang konstan hingga batas akhir waktu inkubasi yang telah ditentukan. Fenomena ini diduga terjadi karena selama proses inkubasi mikroorganisme Saccharomyces cerevisiae yang digunakan pada fermentasi ketan berada pada fase stasioner (Hikmah, 2018). Fase stasioner merupakan fase pertumbuhan dan kematian bakteri terjadi secara seimbang sehingga berdampak pada kandungan alkohol yang relatif akan bernilai konstan seperti yang ditunjukkan pada tabel 1 .

Tabel 1. Pengaruh Waktu Inkubasi dan Persentase Ragi Terhadap Kadar Alkohol yang dihasilkan.

\begin{tabular}{ccccc}
\hline No. & Waktu & \multicolumn{3}{c}{ Kadar Alkohol (\%) } \\
Inkubasi & Ragi & Ragi & Ragi \\
& (jam) & $\mathbf{0 , 5 \%}$ & $\mathbf{1 \%}$ & $\mathbf{1 , 5 \%}$ \\
\hline 1. & 24 & 0.73 & 1.08 & 1.38 \\
2. & 38 & 0.92 & 1.25 & 1.63 \\
3. & 72 & 0.92 & 1.25 & 1.63 \\
\hline
\end{tabular}

Adapun karakteristik persentase kadar alkohol yang dihasilkan pada proses fermentasi ketan (Tabel 1) menunjukkan bahwa pada saat sampel diinkubasi selama 24-37 jam sampel tersebut mengalami peningkatan persentase alkohol, namun ketika waktu inkubasi 38-72 jam, sampel tersebut tidak lagi mengalami peningkatan persentase alkohol dan cenderung memiliki nilai yang konstan atau pada fase stasioner.

\section{SIMPULAN DAN SARAN}

Sistem monitoring kandungan gas alkohol pada fermentasi ketan berbasis sensor TGS 2620 pada Arduino Uno dan modul Data Logger mampu mendeteksi kadar alkohol. Adapun karakteristik sensor TGS 2620 yang digunakan memiliki akurasi 98,33\%, presisi sebesar $99,79 \%$, warmup selama 3,75 menit, dan response time 10,83 menit. Hasil monitoring kandungan alkohol pada fermentasi ketan yaitu kadar alkohol akan semakin tinggi seiring dengan penambahan ragi dan waktu inkubasi yang diberikan. Kadar alkohol terukur antara $0,73 \%$ sampai $1,63 \%$.

\section{DAFTAR RUJUKAN}

Abdillah, M. N. (2016). Rancang Bangun Alat Pendeteksi Kualitas Tape Singkong dengan Sensor MQ3 dan Sensor LDR Berbasis fuzzy logic. Universitas Jember.

Aditama, F. A., Zulfikri, L., Mardiana, L., Mulyaningsih, T., \& Qomariyah, Nurul Wirawan, R. (2020). Electronic nose sensor development using ANN backpropagation for Lombok Agarwood classification. Res. Agr. Eng.

Antika, E., Susmiati, Y., \& Nuha, F. U. (2018). 
Perbandingan Alat Baca Kadar Bioetanol. Konferensi Nasional Sistem Informasi 2018.

Berlian, Z., Aini, F., \& Ulandari, R. (2016). Kadar Alkohol Pada Tapai Ketan Putih Dan Singkong. Jurnal Biota.

Cahyadi, W. (2006). Analisis dan Aspek Kesehatan Bahan Tambahan Pangan. Bumi Aksara.

Figaro, G. (2003). General Information for TGS Sensors. Figaro Enggineering Inc.

Hikmah, J. (2018). Pengaruh pH dan Suhu Terhadap Aktivitas Antibakteri Bekatul Terfermentasi Oleh Rhixopus Oryzae. Universitas Islam Negeri Malang.

Peraturan Menteri Kesehatan RI Nomor 86/Men,kes/PER/ IV/1997 tentang Minuman Keras, (2018).

Putri, Y. N. (2007). Mempelajari Pengaruh Penyimpanan Tape Ketan Terhadap Daya Terima Konsumen. Institut Pertanian Bogor.

Rohmanto. (2014). Penerapan Sensor TGS 2620 sebagai Pendeteksi Kadar Alkohol pada Produk Pangan Berbasis Mikrokontroller ATMEGA8535. Universitas Lampung.

Satria, V. A., \& Wildan. (2013). Rancang Bangun Alat Ukur Kadar Alkohol Pada Cairan Menggunakan Sensor MQ-3 Berbasis Mikrokontroller AT89S51. Jurnal Fisika Unand. 